\title{
PENGARUH KETIDAKSEIMBANGAN BEBAN PADA RUGI DAYA SALURAN NETRAL JARINGAN DISTRIBUSI TEGANGAN RENDAH
}

\author{
Ahmad Deni Mulyadi \\ Jurusan Teknik Konversi Energi, Politeknik Negeri Bandung \\ Jl. Geger Kalong Hilir, Ciwaruga, Bandung \\ e_mail:deni_m2001@yahoo.com
}

\begin{abstract}
Abstrak
Ketidakseimbangan beban pada suatu sistem jaringan distribusi tenaga listrik selalu terjadi dan penyebab ketidakseimbangan tersebut adalah pada pengaturan beban-beban satu fasa pada pelanggan jaringan tegangan rendah. Akibat ketidakseimbangan beban tersebut muncul arus pada netral trafo. Arus yang mengalir pada netral trafo ini menyebabkan terjadinya losses (rugi-rugi), yaitu losses akibat adanya arus netral pada penghantar netral trafo. Setelah dianalisa, diperoleh bahwa bila terjadi ketidakseimbangan beban sebesar (13,3\%), maka arus netral yang muncul lumayan besar yakni sebesar (108 A) dan losses akibat adanya arus netral pada penghantar netral trafo sebesar (0,36\%).
\end{abstract}

Kata kunci: Pembebanan trafo, Ketidak seimbangan beban, Rugi daya

\section{PENDAHULUAN}

Dari masa ke masa seiring dengan perkembangan ilmu pengetahuan dan kemajuan teknologi, manusia menghendaki kehidupan yang lebih nyaman. Bagi masyarakat modern, energi listrik merupakan kebutuhan primer. Hal ini bisa kita lihat dalam kehidupan sehari-hari energi listrik bermanfaat untuk kebutuhan rumah tangga.

Penyediaan tenaga listrik yang stabil dan kontinyu merupakan syarat mutlak yang harus dipenuhi dalam memenuhi kebutuhan tenaga listrik. Untuk itu, terjadi pembagian bebanbeban yang pada awalnya merata, tetapi karena ketidakserempakan waktu penyalaan bebanbeban tersebut maka menimbulkan ketidakseimbangan beban yang berdampak pada penyediaan tenaga listrik. Ketidakseimbangan beban antara tiap-tiap fasa (fasa $\mathrm{R}$, fasa $\mathrm{S}$, dan fasa $\mathrm{T}$ ) inilah yang menyebabkan mengalirnya arus di penghantar netral trafo.

\section{METODOLOGI}

Pada pengukuran ketidakseimbangan beban transformator distribusi tegangan rendah ini, dilakukan dalam dua waktu pengukuran yakni pada siang hari dan pada saat beban puncak untuk membandingankan ketidakseimbangan bebannya.

\section{- Perhitungan Arus Beban Penuh} Transformator

Daya transformator bila ditinjau dari sisi tegangan tinggi (primer) dapat dirumuskan sebagai berikut:

$$
\mathrm{S}=\sqrt{3} . \mathrm{V} . \mathrm{I}
$$

dimana:

$$
\begin{aligned}
& \mathrm{S}=\text { daya transformator }(\mathrm{kVA}) \\
& \mathrm{V}=\text { tegangan sisi primer transformator }(\mathrm{kV}) \\
& \mathrm{I}=\text { arus jala-jala }(\mathrm{A})
\end{aligned}
$$

Sehingga untuk menghitung arus beban penuh (full load) dapat menggunakan rumus :

dimana:

$$
\mathrm{I}_{\mathrm{FL}}=\frac{\mathrm{s}}{\sqrt{\mathrm{i} i \mathrm{~V}}}
$$

$\mathrm{I}_{\mathrm{FL}}=$ arus beban penuh $(\mathrm{A})$

$\mathrm{S}=$ daya transformator $(\mathrm{kVA})$

$\mathrm{V}=$ tegangan sisi sekunder transformator $(\mathrm{kV})$

\section{$>$ Losses Akibat Adanya Arus Netral pada Penghantar Netral Transformator.}

Sebagai akibat dari ketidakseimbangan beban antara tiap-tiap fasa pada sisi sekunder trafo (fasa R, fasa S, fasa T) mengalirlah arus di netral trafo. Arus yang mengalir pada penghantar netral trafo ini menyebabkan losses (rugi-rugi). Losses 
pada penghantar netral trafo ini dapat dirumuskan sebagai berikut:

$$
\mathrm{P}_{\mathrm{N}}=\mathrm{I}_{\mathrm{N}}^{2} \cdot \mathrm{R}_{\mathrm{N}}
$$

dimana:

$\mathrm{P}_{\mathrm{N}}=$ losses pada penghantar netral trafo (watt)

$\mathrm{I}_{\mathrm{N}} \quad=$ arus yang mengalir pada netral trafo (A)

$\mathrm{R}_{\mathrm{N}}=$ tahanan penghantar netral trafo $(\Omega)$

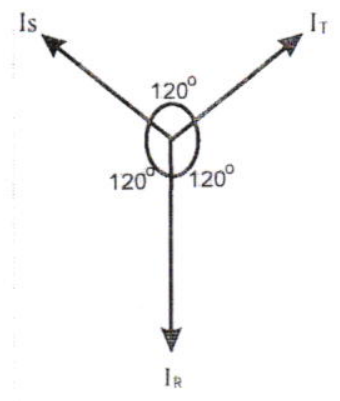

(a)

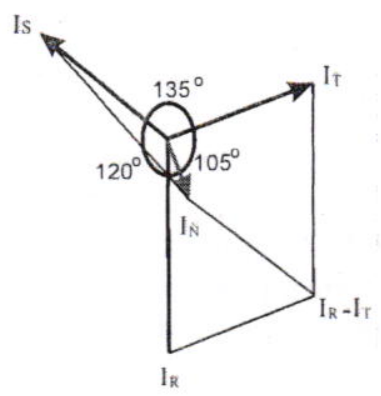

(b)
Gambar 1. Vektor Diagram Arus

Gambar 1(a) menunjukkan vektor diagram arus dalam keadaan seimbang. Di sini terlihat bahwa penjumlahan ketiga vektor arusnya $\left(I_{R}, I_{S}, I_{T}\right)$ adalah sama dengan nol sehingga tidak muncul $\operatorname{arus~netral}\left(\mathrm{I}_{\mathrm{N}}\right)$.

Sedangkan gambar 1(b) menunjukkan vektor diagram arus yang tidak seimbang. Di sini terlihat bahwa penjumlahan ketiga vektor arusnya $\left(I_{R}, I_{S}, I_{T}\right)$ tidak sama dengan nol sehingga muncul sebuah besaran yaitu arus netral $\left(\mathrm{I}_{\mathrm{N}}\right)$ yang besarnya bergantung dari seberapa besar faktor ketidakseimbangannya.

\section{Penyaluran dan Susut Daya}

Misalnya daya sebesar P disalurkan melalui suatu saluran dengan penghantar netral, apabila pada penyaluran daya ini arus-arus fasa dalam keadaan seimbang, maka besarnya daya dapat dinyatakan sebagai berikut:

$\mathrm{P}=3 \cdot[\mathrm{V}] \cdot[\mathrm{I}] \cdot \cos \phi$

dimana:

$$
\begin{array}{ll}
\mathrm{P} & =\text { daya pada ujung kirim } \\
\mathrm{V} & =\text { tegangan pada ujung kirim } \\
\cos \phi & =\text { faktor daya }
\end{array}
$$

Daya yang sampai ujung terima akan lebih kecil dari P karena terjadi penyusutan dalam saluran. Jika I adalah besaran arus fasa dalam penyaluran daya sebesar P pada keadaan seimbang, maka pada penyaluran daya yang sama tetapi dengan keadaan tak seimbang besarnya arus-arus fasa dapat dinyatakan dengan koefisien a, b, dan c sebagai berikut :

$$
\begin{aligned}
& {\left[I_{R}\right]=a \cdot[I]} \\
& {\left[I_{S}\right]=b \cdot[I]} \\
& {\left[I_{T}\right]=c .[I]}
\end{aligned}
$$

Dengan $I_{R}, I_{S}$ dan $I_{T}$ berturut-turut adalah arus di fasa $\mathrm{R}, \mathrm{S}$ dan $\mathrm{T}$. Bila faktor daya di ketiga fasa dianggap sama walaupun besarnya arus berbeda, maka besarnya daya yang disalurkan dapat dinyatakan sebagai:

$$
\mathrm{P}=(\mathrm{a}+\mathrm{b}+\mathrm{c}) \cdot[\mathrm{V}] \cdot[\mathrm{I}] \cdot \cos \phi
$$

Apabila persamaan (6) dan persamaan (4) menyatakan daya yang besarnya sama, maka dari kedua persamaan itu dapat diperoleh persyaratan untuk koefisien a, b, dan c yaitu :

$$
a+b+c=3
$$

dimana pada keadaan seimbang, nilai $\mathrm{a}=\mathrm{b}=\mathrm{c}=1$

\section{HASIL DAN PEMBAHASAN}

\section{Pengumpulan Data}

Spesifikasi Gardu Tembok CDR adalah sebagai berikut :

$\begin{array}{ll}\text { Buatan Pabrik } & : \text { TRAFINDO } \\ \text { Tipe } & : \text { Indoor } \\ \text { Daya } & : 630 \mathrm{kVA} \\ \text { Tegangan Kerja } & : 22 / 21 / 20 / 19 / 18 \mathrm{kV} / / 400 \mathrm{~V} \\ \text { Arus Nominal P } & : 18,18 \mathrm{~A} \\ \text { S } & : 909,32 \mathrm{~A} \\ \text { Hubungan } & : \text { Dyn5 } \\ \text { Trafo } & : 1 \times 3 \text { phasa }\end{array}$




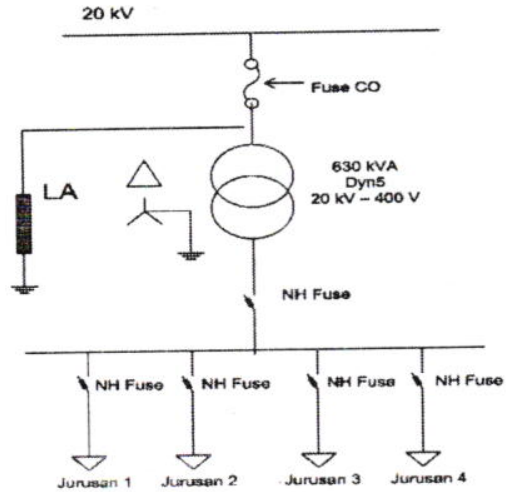

Gambar 2. Single line trafo distribusi 3 Fasa $630 \mathrm{kVA}$

Tabel 1. Pengukuran Beban Siang Hari

\begin{tabular}{|c|c|c|}
\hline \multicolumn{3}{|c|}{ Pengukuran Pagi dan Siang Hari } \\
\hline \multicolumn{3}{|c|}{ Tegangan (volt) } \\
\hline$V_{R-N}=222$ & \multicolumn{2}{|c|}{$V_{R-S}=386$} \\
\hline $\mathrm{V}_{\mathrm{S}-\mathrm{N}}=222$ & \multicolumn{2}{|c|}{$V_{R-T}=385$} \\
\hline $\mathrm{V}_{\mathrm{T}-\mathrm{N}}=221$ & \multicolumn{2}{|c|}{$V_{S-T}=381$} \\
\hline \multicolumn{3}{|c|}{ Arus Total (amper) } \\
\hline$I_{R}=445$ & \multicolumn{2}{|c|}{$I_{T}=311$} \\
\hline$I_{S}=410$ & \multicolumn{2}{|c|}{$I_{N}=108$} \\
\hline \multicolumn{3}{|c|}{ Arus Jurusan (amper) } \\
\hline$I_{R I}=14$ & $I_{R 2}=18$ & $I_{R .3}=5$ \\
\hline$I_{S 1}=5$ & $I_{\mathrm{S} 2}=21$ & $\mathrm{I}_{\mathrm{S} 3}=11$ \\
\hline $\mathrm{I}_{\mathrm{Tl}}=10$ & $\mathrm{I}_{\mathrm{T} 2}=14$ & $\mathrm{I}_{\mathrm{T} 3}=6$ \\
\hline $\mathrm{I}_{\mathrm{N} 1}=10$ & $I_{\mathrm{N} 2}=10$ & $\mathrm{I}_{\mathrm{N} 3}=10$ \\
\hline$I_{R 4}=108$ & $I_{R 5}=123$ & $I_{R 6}=136$ \\
\hline$I_{S 4}=105$ & $I_{S 5}=82$ & $I_{S 6}=132$ \\
\hline $\mathrm{I}_{\mathrm{T} 4}=127$ & $I_{T 5}=126$ & $\mathrm{I}_{\mathrm{T} 6}=175$ \\
\hline$I_{\mathrm{N} 4}=36$ & $I_{\mathrm{N} 5}=29$ & $I_{\mathrm{NG}}=23$ \\
\hline
\end{tabular}

Tabel 2. Pengukuran Beban Malam Hari

\begin{tabular}{|c|c|}
\hline \multicolumn{2}{|c|}{ Pengukuran Pagi dan Siang Hari } \\
\hline \multicolumn{2}{|c|}{ Tegangan (volt) } \\
\hline$V_{R-N}=226$ & $V_{R-S}=386$ \\
\hline $\mathrm{V}_{\mathrm{S}-\mathrm{N}}=224$ & $V_{R-T}=381$ \\
\hline$V_{T-N}=221$ & $V_{S-T}=387$ \\
\hline \multicolumn{2}{|c|}{ Arus Total (amper) } \\
\hline$I_{R}=674$ & $\mathrm{I}_{\mathrm{T}}=643$ \\
\hline $\mathrm{I}_{\mathrm{S}}=700$ & $I_{N}=161$ \\
\hline \multicolumn{2}{|c|}{ Arus Jurusan (amper) } \\
\hline$I_{R I}=19$ & \begin{tabular}{l|l}
22 & $\mathrm{I}_{\mathrm{R} 3}=14$ \\
\end{tabular} \\
\hline
\end{tabular}

\begin{tabular}{|l|l|l|}
\hline $\mathrm{I}_{\mathrm{S} 1}=5$ & $\mathrm{I}_{\mathrm{S} 2}=40$ & $\mathrm{I}_{\mathrm{S} 3}=11$ \\
\hline $\mathrm{I}_{\mathrm{Tl}}=24$ & $\mathrm{I}_{\mathrm{T} 2}=22$ & $\mathrm{I}_{\mathrm{T} 3}=2$ \\
\hline $\mathrm{I}_{\mathrm{N} 1}=15$ & $\mathrm{I}_{\mathrm{N} 2}=36$ & $\mathrm{I}_{\mathrm{N} 3}=15$ \\
\hline $\mathrm{I}_{\mathrm{R} 4}=115$ & $\mathrm{I}_{\mathrm{R} 5}=176$ & $\mathrm{I}_{\mathrm{R} 6}=158$ \\
\hline $\mathrm{I}_{\mathrm{S} 4}=120$ & $\mathrm{I}_{\mathrm{S} 5}=113$ & $\mathrm{I}_{\mathrm{S} 6}=168$ \\
\hline $\mathrm{I}_{\mathrm{T} 4}=153$ & $\mathrm{I}_{\mathrm{T} 5}=168$ & $\mathrm{I}_{\mathrm{T} 6}=177$ \\
\hline $\mathrm{I}_{\mathrm{N} 4}=50$ & $\mathrm{I}_{\mathrm{N} 5}=37$ & $\mathrm{I}_{\mathrm{N} 6}=28$ \\
\hline
\end{tabular}

Ukuran kawat untuk penghantar netral trafo adalah $70 \mathrm{~mm}^{2}$ dengan $\mathrm{R}=0,5049 \Omega / \mathrm{km}$, sedangkan untuk kawat penghantar fasanya adalah $3 \times 70 \mathrm{~mm}^{2}$ dengan $\mathrm{R}_{\text {ekivalen }}=0,1683 \Omega /$ $\mathrm{km}$.

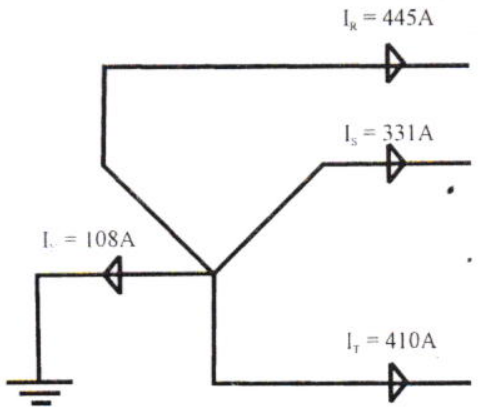

Gambar 3. Skema aliran arus di sisi sekunder trafo pada siang hari

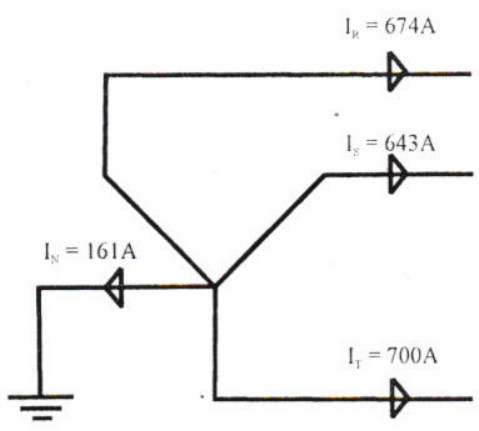

Gambar 4. Skema aliran arus di sisi sekunder trafo pada malam hari

\section{Analisa Pembebanan Trafo}

Berdasarkan data yang didapat:

$$
\mathrm{S} \quad=630 \mathrm{kVA}
$$

$\mathrm{V}=0,4 \mathrm{kV}$ phasa - phasa, dengan menggunakan persamaan(2) maka didapat arus beban penuh sebagai berikut:

$$
\mathrm{I}_{\mathrm{FL}}=\frac{\mathrm{s}}{\sqrt{\mathrm{S} V}}=\frac{630}{\sqrt{3} \cdot 0,4}=909,32 \mathrm{~A}
$$


Sedangkan untuk arus rata-rata siang dan arus rata-rata malam adalah sebagai berikut :

$$
\begin{aligned}
& I_{\text {rata siang }}=\frac{445+410+311}{3}=388,66 \mathrm{~A} \\
& I_{\text {rata malam }}=\frac{674+700+643}{3}=672,33 \mathrm{~A}
\end{aligned}
$$

Perhitungan untuk persentase pembebanan trafo adalah:

a. Pada siang hari:

$$
\frac{\text { Irata siang }}{I \text { fl }}=\frac{388,66}{909,32}=42,74 \%
$$

b. Pada malam hari:

$$
\frac{\text { Irata malam }}{I f l}=\frac{672,33}{909,32}=73,94 \%
$$

Dari perhitungan di atas terlihat bahwa pada saat malam hari $(\mathrm{WBP}=$ Waktu Beban Puncak $)$ persentase pembebanan cukup tinggi yaitu $73,94 \%$.

\section{Analisa Ketidakseimbangan Beban pada Trafo}

a. Pada Siang Hari :

Dengan menggunakan persamaan (6), koefisien a, b, dan c dapat diketahui besarnya, dimana besarnya arus fasa dalam keadaan seimbang ( I ) sama dengan besarnya arus rata-rata $\left(\mathrm{I}_{\text {raxia }}\right)$.

$$
\begin{aligned}
& \mathrm{I}_{\mathrm{R}}=\underline{\mathrm{a} .} \text { I maka, } \mathrm{a}=\frac{I R}{\text { Irata siang }}=\frac{445}{388,66}=1,144 \\
& \mathrm{I}_{\mathrm{S}}=\mathrm{b} \text {. I maka, } \mathrm{b}=\frac{I S}{\text { Irata siang }}=\frac{311}{388,66}=0,800 \\
& \mathrm{I}_{\mathrm{T}}=\mathrm{c} . \mathrm{I} \text { maka, } \mathrm{c}=\frac{I T}{\text { Irata siang }}=\frac{\mathbf{4 1 0}}{\mathbf{3 8 8 , 6 6}}=1,055
\end{aligned}
$$

Pada keadaan seimbang, besarnya koefisien a, b dan c adalah 1. Dengan demikian, rata-rata ketidakseimbangan beban (dalam \%) adalah:

$$
\begin{aligned}
& =\frac{\{a-1+b-1+c-1\}}{3} \times 100 \% \\
& =\frac{\{|1,144-1|+|0,8-1|+|1,055-1|\}}{3} \times 100 \% \\
& =13,3 \%
\end{aligned}
$$

b. Pada Malam Hari :

Dengan menggunakan persamaan (6), koefisien a, b, dan c dapat diketahui besarnya, dimana besarnya arus fasa dalam keadaan seimbang ( I ) sama dengan besarnya arus rata-rata $\left(\mathrm{I}_{\text {rata }}\right)$.

$$
\begin{aligned}
& \mathrm{I}_{\mathrm{R}}=\mathrm{a} . \mathrm{I} \text { maka, } \mathrm{a}=\frac{I R}{\text { Irata malam }}=\frac{674}{672,33}=1,002 \\
& \mathrm{I}_{\mathrm{S}}=\underline{\mathrm{b} .} . \mathrm{I} \text { maka, } \mathrm{b}=\frac{I S}{\text { Irata malam }}=\frac{643}{672,33}=0,956 \\
& \mathrm{I}_{\mathrm{T}}=\mathrm{c} . \mathrm{I} \text { maka, } \mathrm{c}=\frac{I T}{\text { Irata malam }}=\frac{700}{672,33}=1,041
\end{aligned}
$$

Pada keadaan seimbang, besarnya koefisien a, b dan c adalah 1. Dengan demikian, rata-rata ketidakseimbangan beban (dalam \%) adalah:

$$
\begin{aligned}
& =\frac{\{a-1+b-1+c-1\}}{3} \times 100 \% \\
& =\frac{\{|1,002-1|+|0,956-1|+|1,041-1|\}}{3} \times 100 \% \\
& =2,9 \%
\end{aligned}
$$

Dari perhitungan di atas terlihat bahwa baik pada siang hari maupun malam hari, ketidakseimbangan beban cukup baik $(<25 \%)$, hal ini disebabkan karena penggunaan beban yang merata di antara konsumen.

\section{Analisa Losses Akibat Adanya Arus Netral pada Penghantar Netral Trafo}

a. Pada Siang Hari:

Dari tabel pengukuran, dan dengan menggunakan persamaan (3), losses akibat adanya arus netral pada penghantar netral trafo dapat dihitung besarnya, yaitu:

$$
\begin{aligned}
\mathrm{P}_{\mathrm{N}} & =\mathrm{I}_{\mathrm{N}}^{2} \cdot \mathrm{R}_{\mathrm{N}}=(108)^{2} \cdot 0,5049 \\
& =5889,15 \text { Watt } \approx 5,88 \mathrm{~kW}
\end{aligned}
$$

dimana daya aktif trafo $(\mathrm{P})$ :

$\mathrm{P}=\mathrm{S} \cdot \cos \varphi$,

dimana $\cos \varphi$ yang digunakan adalah 0,85

$\mathrm{P}=630 \times 0,85=535,5 \mathrm{~kW} / \mathrm{km}$

Sehingga, persentase losses akibat adanya arus netral pada penghantar netral trafo adalah:

$$
\begin{aligned}
\% \mathrm{P}_{\mathrm{N}} & =\frac{P N}{P} \times 100 \%=\frac{5,88 \mathrm{~kW}}{535,5 \mathrm{~kW}} \times 100 \% \\
& =1,09 \%
\end{aligned}
$$

b. Pada Malam Hari: 
Dari tabel pengukuran, dan dengan menggunakan persamaan (3), losses akibat adanya arus netral pada penghantar netral trafo dapat dihitung besarnya, yaitu:

$$
\begin{aligned}
\mathrm{P}_{\mathrm{N}} & =\mathrm{I}_{\mathrm{N}}^{2} \cdot \mathrm{R}_{\mathrm{N}}=(161)^{2} \times 0,5049 \\
& =13087,51 \mathrm{Watt} \approx 13,087 \mathrm{~kW} / \mathrm{km}
\end{aligned}
$$

dimana daya aktif trafo $(\mathrm{P})$ :

$\mathrm{P}=\mathrm{S} \cdot \cos \varphi$, dimana $\cos \varphi$ yang digunakan adalah 0,85

$\mathrm{P}=630 \times 0,85=535,5 \mathrm{~kW}$

Sehingga, persentase losses akibat adanya arus netral pada penghantar netral trafo adalah:

$$
\begin{aligned}
\% \mathrm{P}_{\mathrm{N}} & =\frac{P N}{P} \times 100 \%=\frac{13,087 \mathrm{~kW}}{535,5 \mathrm{~kW}} \times 100 \% \\
& =2,44 \%
\end{aligned}
$$

Tabel 4.2 Persentase Ketidakseimbangan Beban

\begin{tabular}{|l|l|l|l|c|}
\hline Waktu & $\begin{array}{l}\mathrm{I}_{\mathrm{N}} \\
(\mathrm{A})\end{array}$ & $\begin{array}{l}\mathrm{P}_{\mathrm{N}} \\
(\mathrm{KW})\end{array}$ & $\begin{array}{l}\mathrm{P}_{\mathrm{N}} \\
(\%)\end{array}$ & $\begin{array}{l}\text { Ketidakseimbangan } \\
\text { Beban }(\%)\end{array}$ \\
\hline Siang & 108 & 5,88 & 1,09 & 13,3 \\
\hline Malam & 161 & 13,087 & 2,44 & 2,9 \\
\hline
\end{tabular}

Pada Tabel 4.2 terlihat bahwa semakin besar arus netral yang mengalir di penghantar netral trafo $\left(\mathrm{I}_{\mathrm{N}}\right)$ maka semakin besar losses pada penghantar netral trafo $\left(\mathrm{P}_{\mathrm{N}}\right)$. Dengan semakin besar arus netral dan losses di trafo maka effisiensi trafo menjadi turun.

Berdasarkan analisa data di atas, terlihat bahwa pada siang hari ketidakseimbangan beban pada trafo lebih besar dibandingkan dengan pada saat malam hari. Perbedaan tersebut dikarenakan pada siang hari penggunaan beban listrik tidak merata.

\section{KESIMPÜLAN}

Berdasarkan hasil pengamatan yang dilakukan di bagian Distribusi PT. PLN (Persero) Distribusi Jawa Barat dan Banten Unit Pelayanan dan Jaringan Cimahi Kota pada saat pengukuran beban adalah sebagai berikut :
1. Untuk membandingkan penggunaan beban, pengukuran cukup dilakukan dua kali pengukuran yakni pada siang hari dan pada saat WBP (waktu beban puncak).

2. Pada salah satu gardu yakni gardu CDR, pembebanan pada siang hari maupun malam hari, ketidakseimbangan bebannya cukup baik yakni $<25 \%$, hal ini disebabkan karena penggunaan beban yang cukup merata di antara konsumen.

3. Semakin besar ketidakseimbangan beban pada transformator maka arus netral dan losses di saluran netral transformator semakin besar.

4. Salah satu tujuan dilakukanya pengecekan maupun pengukuran beban adalah untuk mengatasi arus netral dan losses yang disebabkan ketidakseimbangan beban, yang mana hal tersebut dapat menyebabkan efisiensi transformator menjadi berkurang.

5. Salah satu cara mengatasi losses arus netral adalah membuat pembebanan seimbang mungkin dan dengan membuat ukuran penghantar netral dan fasa yang sama.

\section{DAFTAR PUSTAKA}

1. Abdul Kadir, Distribusi dan Utilisasi Tenaga Listrik. Jakarta: UI - Press, 2000.

2. Suhadi, dkk. 2008. Teknik Distribusi Tenaga Listrik Jilid 1 untuk SMK. Jakarta :Direktorat Pembinaan Sekolah Menengah Kejuruan, Direktorat Jenderal Manajemen Pendidikan Dasar dan Menengah, Departemen Pendidikan Nasional.

3. Zuhal. 1991. Dasar Teknik Tenaga Listrik dan Elektronika Daya. Bandung : Penerbit ITB.

4. SL.Upal, Electrical Power, Khanna Publisher, Delhi-6, 1985

5. BL. Theraja, Textbook of electrical thechnology, Publication of Nirja Construction \& Development Co., New Delhi, 2007 